\title{
Sedative Effect and Standardization Parameters of Herbal Medicinal Product Obtained from the Ocimum americanum L. Herb
}

Shanaida M. ${ }^{\square}$, Golembiovska O. ${ }^{2}$, Jasicka-Misiak I. ${ }^{3}$, Oleshchuk O. ${ }^{1}$, Beley N. ${ }^{1}$, Kernychna I. ${ }^{1}$,Wieczorek P.P. ${ }^{3}$

11. Horbachevsky Ternopil National Medical University

${ }^{2}$ Institute of Organic Chemistry National

Academy of Sciences of Ukraine

${ }^{3}$ Opole University

Received 9 September, 2020, accepted 1 February, 2021

Abstract Sedative phytomedications continue to play an important role in the management of a considerable amount of anxiety symptoms because of the various side effects of synthetic sedatives and tranquilizers. However, developing new herbal drugs needs their appropriate quality control according to the relevant requirements. The aim of the study was to determine the sedative properties of the tinctures obtained from the American basil (Ocimum americanum L., Lamiaceae Martinov family) herb and to develop the standardization parameters for the promising herbal medicinal product. The open field test was used to evaluate the sedative effect of the prepared tinctures: (1) with the added of O. americanum essential oil (OATEs) and (2) without adding O. americanum essential oil (OAT). The standardization parameters for the OATEs were developed using validated High-Performance Thin Layer Chromatography (HPTLC) and High-Performance Liquid Chromatography (HPLC) methods. The HPTLC analysis was used for the chromatographic fingerprints of polyphenols and for identifying linalool in the OATEs. The HPLC analysis found the significant content of rosmarinic acid (RA) $(0.26 \%)$ in the OATEs. In conclusion, the developed OATEs can be considered as the new herbal medicinal product with significant sedative properties.

Keywords American basil-herb-tincture-sedative activity-polyphenols-linalool-chromatographic analysis

\section{INTRODUCTION}

Rational phytotherapy is a modern concept of herbal medicines that uses the standardized herbal medicinal products (Choudhary et al., 2011). A significant number of components in the tinctures and extracts from the plant raw materials are accompanied by the problem of their standardization. Quality control of herbal drugs should be done according to the requirements of relevant regulations (American Herbal Pharmacopoeia, 2011; European Pharmacopoeia, 2016).

Anxiety and depression are the important health problems in a modern society leading to low quality of life (Gutiérrez et al., 2015). Sedatives continue to play an important role in managing many anxiety symptoms in the context of medical illness. However, the side effects of synthetic anxiolytic drugs such as various syndromes of withdrawal, dependencies, and impairment of cognitive function and memory are of concern to physicians and scientists. Searching of new sources of plant raw material with anxiolytic action among the Lamiaceae Martinov species is a promising direction of scientific investigations is the area of phytochemistry and ethnopharmacology (Rabbani et al., 2015; Caputo et al., 2018; Bittner Fialová et al., 2019). Pharmaceutical industries produce a lot of phytomedications of a sedative action using the aerial parts of the Lamiaceae representatives such as Leonurus cardiaca, Melissa officinalis, Menthaxpiperita, Lavandula angustifolia, and so on (Kowalczyk et al., 2012; Derzhavnyi rejestr, 2020).

Tincture, as a water-ethanol extract of a plant material being prepared at room temperature, preserves the complex as non-volatile so as volatile compounds (Doughari, 2012). The quality of tinctures or any herbal medicinal products primarily depends on the presence and content of the certain ingredients with proven biological activity (Hudz et al., 2019). 
High-Performance Thin Layer Chromatography (HPTLC) and High-Performance Liquid Chromatography (HPLC) methods have become increasingly practiced for routine analysis of herbal medicinal products obtained from the representatives of Mint Family (Staszek et al., 2013; Shafqatullah et al., 2014; Asha et al., 2015) as well as synthetic drugs (Logoyda et al., 2018).

American basil (O. americanum L.) belongs to the genus Ocimum L., subfamily Nepetoideae Burnett, family Lamiaceae. It is an annual essential oil-bearing plant native to Africa and Southeast Asia used locally as a spice or ornamental plant as well as a sedative, digestive, and anti-inflammatory remedy (The Genus Ocimum, 2006; Shanaida et al., 2017). Nowadays, this species is successfully naturalized on most continents. The aerial part of $O$. americanum accumulates several valuable groups of primary and secondary metabolites such as terpenoids, polyphenols, and amino acids, which are perspective for the sedative purpose (Koteswar and Babu, 2011; Shanayda, 2012; Shanaida et al., 2017; Shanaida and Golembiovska, 2018; Shanaida et al., 2018). Linalool (49.84\%) that possesses significant sedative properties (Linck et al., 2009; Aprotosoaie et al., 2014) was the major component of essential oil hydrodistillated from the 0 . americanum herb collected in Ukraine (Shanayda, 2012). Rosmarinic acid (19.59 mg/g) was revealed by HPTLC as a predominant polyphenolic compound in the methanol extract of this plant raw material (Shanaida et al., 2020). However, the raw material of this species is not included in any Pharmacopoeias (American Herbal Pharmacopoeia, 2011; European Pharmacopoeia, 2016). Thus, studying the sedative properties of tinctures obtained from the herb of $O$. americanum and developing their quality parameters can be considered as quite a perspective.

The aim of the study was to determine the sedative effects of the tinctures obtained from the Ocimum americanum herb and to develop the standardization parameters for the promising herbal medicinal product by the validated HPTLC and HPLC methods.

\section{MATERIALS AND METHODS}

\section{Plant material and preparing of tinctures}

The herb of 0 . americanum was collected from the experimental plots in Ternopil region (Ukraine). Plants were grown from the seeds obtained from the collection of $M$. Hryshko National Botanical Garden (Kyiv, Ukraine). A voucher specimen (OM: 10011) has been deposited in the Herbarium of I. Horbachevsky Ternopil National Medical University for further references. The herb was harvested during the flowering stage, then dried in the shadow at $25-35^{\circ} \mathrm{C}$. Two tinctures were prepared from the $O$. americanum herb using $70 \%$ ethanol (V/V): (1) with added O. americanum essential oil (OATEs) and (2) without adding O. americanum essential oil (OAT).
The powdered herb of the plant $(20.0 \mathrm{~g})$ was macerated with $200 \mathrm{~mL}$ ethanol $(70 \%, V /$ ) at room temperature for 24 hours using forced periodic stirring. The supernatant was separated and filtered with a Buchner funnel, then placed for 2 days in the refrigerator (at $8-10^{\circ} \mathrm{C}$ ) for the sedimentation of ballast substances. The total ratio of raw material and tincture obtained by the described method was 1:10 (if necessary, $70 \%$ ethanol was added to get $200 \mathrm{~mL}$ of OAT). The OATEs was obtained by the adding $0.5 \mathrm{~mL}$ of $O$. americanum essential oil hydrodistillated from its herb to $100 \mathrm{~mL}$ of OAT. The volume of $O$. americanum essential oil chosen for dissolving into basic ethanol extract was analogous to the dose of Mentha $\times$ piperita (Lamiaceae) essential oil, which is added to the 'Menthae piperitae tincture' to enhance its pharmacological effect (Derzhavnyi reiestr, 2020). The essential oil of O. americanum was first dissolved in ethanol $(96 \%, V / V)$ in the ratio $1: 4$, and then this solution was added to $100 \mathrm{~mL}$ of OAT to obtain a homogeneous solution.

\section{Drugs and chemicals}

Ethanol, ethyl acetate, and formic acid were purchased from Merck (Kennborough, NJ, USA). Aluminium chloride, toluene, Tween-80, anisaldehyde were purchased from Sigma-Aldrich (Germany). HPLC-grade acetonitrile, methanol, and trifluoracetic acid were purchased from Sigma-Aldrich (USA). Double-distilled water prepared using a Milli-Q water purification system (Millipore system). Silica gel plates for HPTLC and reference standards such as linalool, rutin, caffeic acid, and rosmarinic acid (RA) were purchased from Merck (Germany). Diazepam ( $5 \mathrm{mg} / \mathrm{mL}$ ) was obtained from the Elegant (India). All the chemicals used in this study were of analytical grade.

\section{Open field test}

The spontaneous locomotor activities of experimental animals were assessed according to Linck et al. (2009) and Sarker Apu et al. (2013). Open field device consisted of a wooden field of one square meter with a series of squares and holes at their intersection; the floor was divided into 25 marked small squares of equal dimensions $(20 \times 20 \mathrm{~cm})$. This device was placed in a dimly lit room.

Animals: male albino rats (220-240 g) were obtained from the Vivarium of I. Horbachevsky Ternopil National Medical University (Ukraine). Animals were kept in the standard laboratory conditions: relative humidity $55 \pm 5 \%$; room temperature $22 \pm 2^{\circ} \mathrm{C}$ under a $12 \mathrm{~h}$ light/dark cycle. The animals were provided with standard diet and clean water ad libitum during acclimatization period. They were fasted overnight, with free access to water before the experiments. All the experimental animals were conformed to internationally accepted standards, which were approved by the Bioethical Committee of I. Horbachevsky Ternopil National Medical University, in accordance with 'Ethical Principles and Guidelines for Experiments on Animals' (2005). 
The tested animals were randomly divided into four groups $(n=6)$. The rats were fasted for $12 \mathrm{~h}$ before the experiment. The tinctures were dissolved in the vehicle (1\% solution of Tween-80 in distilled water) to obtain the dose $100 \mathrm{mg} / \mathrm{kg}$ body weight, calculated in terms of dry residue of tincture. Each group of animals received a particular treatment. Group I: negative control (vehicle). Group II: treatment with OAT. Group III: treatment with OATEs. Group IV: positive control (reference drug Diazepam at a dose of $0.55 \mathrm{mg}$ / $\mathrm{kg}$ body weight). After one hour of the treatment, each animal was placed individually at the centre of the device and observed for $3 \mathrm{~min}$ to count the number of actions. The open field arena was thoroughly cleaned between each test to avoid the influence of the urine odours and faeces of the previous animal.

\section{HPTLC analysis of OATEs}

The HPTLC method was performed as described by Shanaida et al. (2020) with some modifications. $5 \mu \mathrm{L}$ of OATEs and 10 $\mu \mathrm{L}$ of standard solutions $(0.25 \mathrm{mg} / \mathrm{mL}$ of phenolic compounds and $5 \mu \mathrm{L} / \mathrm{mL}$ of linalool) were applied to HPTLC plates using an automatic HPTLC application device (Linomat 5, CAMAG, Muttenz, Switzerland). The chromatographic separation was performed on $20 \times 10 \mathrm{~cm}$ HPTLC plates. Two mobile phases were used for eluting process: the ethyl acetate - toluene (5:95, V/M ) was used for method A, and the ethyl acetate formic acid - water (15:1:1, V/V) was applied for method $B$. The chromatographic plates were evaluated after derivatization with anisaldehyde reagent (method $A$ ) or with $1 \%$ aluminium chloride solution in methanol (method $B$ ). The resulting bands were observed under the daylight (method $A$ ) and with UV at 254 and $366 \mathrm{~nm}$. The obtained chromatograms were analysed using HPTLC software (vision CATS, CAMAG). The compounds were identified using their $\mathrm{R}_{f}$ values and colours of the fluorescence comparatively to those of the reference standards. The applied HPTLC method was validated using specificity and robustness parameters.

\section{HPLC analysis of OATEs}

The quantitative analysis of RA in the OATEs was performed with Shimadzu HPLC-DAD system (Shimadzu, Japan). Good separation was achieved by a Phenomenex Luna C18 column (Phenomenex Inc., 250 x $4.6 \mathrm{~mm}$ i.d., $5 \mu \mathrm{m}$ particle size) at $35^{\circ} \mathrm{C}$. The UV absorption spectra of the reference standards and test samples were recorded in the range from 190 to 400 $\mathrm{nm}$. The mobile phase consisted of two solutions: A $(0.1 \%$ trifluoroacetic acid in water) and B (0.1\% trifluoroacetic acid in acetonitrile). The flow rate was $1.0 \mathrm{~mL} / \mathrm{min}$ and injection volume was $5 \mu \mathrm{L}$. The developed HPLC method for analysis of RA content in the OATEs was validated according to the linearity, specificity, limit of detection (LOD), limit of quantification (LOQ), precision, accuracy, and robustness parameters.

\section{Statistical analysis}

The variables for parametric data were analysed by oneway analysis of variance (ANOVA). Statistical analyses were performed using Statistica 12 software (StatSoft Inc., Tulusa, OK, USA). The data were expressed as mean \pm standard error of the mean (SEM). The statistical significance was set at $p \leq 0.05$.

\section{RESULTS AND DISCUSSION}

\section{Sedative activity of OAT and OATEs}

The obtained OATEs demonstrated the noticeable sedative effect when compared to OAT for all the studied parameters in the open field test (Table 1). Anxiety level of animals after the single administration of OATEs decreased significantly. Sedative effect for OAT compared to Diazepam was observed only for the influence on defecation. Thus, adding essential oils of $O$. americanum to OAT led to increasing sedative activity. It was established that linalool as a predominant compound of O. americanum essential oil (Shanayda, 2012) added to tincture to obtain OATEs, possess significant sedative properties (Linck et al., 2009). As it can be seen from the Table 1, the number of squares crossed by the rats was the smallest after the treatment with OATEs. The frequency of defecation as an important indicator of anxiety after the OATEs influence was at the same level as a reference drug. The levels of tentative research activities such as vertical racks and examined holes were also the least numerous in the OATEs group compared to OAT and control groups.

\section{Chromatographic analyses and standardization procedures for OATEs}

\section{HPTLC analysis}

The HPTLC method for the qualitative determination of phenolic compounds and linalool in the OATEs was developed for the first time. A number of solvent systems were tried for OATEs chromatographic analysis. The satisfactory resolutions were reached using such solvent systems as ethyl acetate toluene $(5: 95, V /$ ) for linalool (method $A)$ and ethyl acetate - formic acid - water (15:1:1, V/M for phenolic compounds (method B).

The validation of HPTLC procedure for the identification of linalool in the OATEs (method A) included the specificity and robustness studies. During the specificity study, it was revealed that chromatograms of the reference solution had the violet zone of linalool at $R_{f}=0.29$ at daylight (Fig. 1, Table 2 ). The chromatogram of the test solution showed the weak violet zone at the level of linalool spot. The additional violet bands of unknown compounds possessing the specific for terpenoids violet shades were also available at $R_{f}$ values 0.03 , $0.11,0.19$, and 0.85 in the chromatogram of test solutions. The maximum difference in the values of the $R_{f}$ zones of linalool 
Table 1. The influence of tinctures prepared from Ocimum americanum herb on the spontaneous behavior of rats in the open field test $(n=6)$.

\begin{tabular}{|c|c|c|c|c|c|c|}
\hline \multirow{2}{*}{ Group } & \multirow{2}{*}{$\begin{array}{c}\text { Number of } \\
\text { squares crossed }\end{array}$} & \multicolumn{2}{|c|}{ Tentative research activity } & \multicolumn{3}{c|}{ Indicators of anxiety (emotional reactions) } \\
\cline { 3 - 7 } & Vertical racks & Examined holes & Defecations & Urinations & Grooming \\
\hline Control & $32.61 \pm 2.29$ & $9.52 \pm 0.89$ & $5.21 \pm 0.47$ & $1.03 \pm 0.1$ & $0.51 \pm 0.05$ & $2.32 \pm 0.21$ \\
\hline OAT & $29.17 \pm 1.09$ & $8.83 \pm 0.28$ & $4.83 \pm 0.35$ & $0.67 \pm 0.09^{1}$ & $0.5 \pm 0.05$ & $2.33 \pm 0.24$ \\
\hline OATEs & $26.0 \pm 1.02^{1}$ & $8.0 \pm 0.42^{1}$ & $4.5 \pm 0.21$ & $0.5 \pm 0.05^{1}$ & $0.33 \pm 0.02^{1,2}$ & $2.17 \pm 0.19$ \\
\hline Diazepam & $18.5 \pm 0.54^{1}$ & $6.5 \pm 0.18^{1}$ & $3.17 \pm 0.09^{1}$ & $0.5 \pm 0.02^{1}$ & $0^{1}$ & $1.17 \pm 0.04^{1}$ \\
\hline
\end{tabular}

Notation. ${ }^{1}$ - the differences are statistically significant for the values of the control group $(p \leq 0.05) i^{2}$ - the differences are statistically significant for the values of the Diazepam group $(p \leq 0.05)$

Table 2. The results of HPTLC analyses of biologically active compounds in OATEs.

\begin{tabular}{|c|c|c|c|c|c|}
\hline \multicolumn{7}{|c|}{ Compound } & $\mathbf{R}_{\mathrm{f}}$ value & Colour & Presence in OATEs & Presence in essential oil of O. americanum \\
\hline Unknown compound & 0.03 & Violet & + & - \\
\hline Unknown compound & 0.11 & Violet & + & - \\
\hline Unknown compound & 0.19 & Violet & + & + \\
\hline \multicolumn{2}{|c|}{ Linalool } & 0.29 & Violet & + & + \\
\hline Unknown compound & 0.85 & Violet & + & $*$ \\
\hline \multicolumn{2}{|c|}{ Rutin } & 0.09 & Yellow & + & $*$ \\
\hline Unknown compound & 0.14 & Blue & + & $*$ \\
\hline Unknown compound & 0.27 & Yellow & + & $*$ \\
\hline Unknown compound & 0.29 & Blue & + & $*$ \\
\hline Unknown compound & 0.43 & Dark blue & + & + \\
\hline Unknown compound & 0.64 & Blue & Blue & + & $*$ \\
\hline Rosmarinic acid & 0.75 & Blue & + & $*$ \\
\hline Caffeic acid & 0.79 & + & $*$ \\
\hline
\end{tabular}

Notation. ' +' compound is presented; * - parameter was not studied

Table 3. The robustness testing for the identification of linalool in OATEs by HPTLC.

\begin{tabular}{|c|c|c|}
\hline Indicator & $\begin{array}{c}\text { Level of } \\
\text { changes }\end{array}$ & $\begin{array}{c}\text { Rf variability } \\
\text { (RSD, \%) }\end{array}$ \\
\hline $\begin{array}{c}\text { Mobile phase } \\
\text { composition } \\
\text { (ethyl acetate } \\
\text { toluene, } \mathrm{V} / \mathrm{V})\end{array}$ & $5: 95$ & 0.6 \\
\cline { 2 - 3 } & $5.2: 95$ & 1.3 \\
\hline $\begin{array}{c}\text { Development } \\
\text { distance, } \mathrm{Cm}\end{array}$ & $4.8: 95$ & 0.8 \\
\cline { 2 - 3 } & 8 & 1.3 \\
\hline Chamber & $\begin{array}{c}\text { 3 different } \\
\text { containers }\end{array}$ & 1.8 \\
\hline Analysts & $\begin{array}{c}\text { 2 different } \\
\text { analysts }\end{array}$ & 1.3 \\
\hline
\end{tabular}

corresponding the test and reference solutions within one plate was not exceed 0.01 units of $R_{f}$ The robustness studies for method $A$ are presented in Table 3.

The specificity study of the polyphenols identified in OATEs (method B) showed that the chromatograms of reference and test solutions had the prominent blue fluorescent zone of RA (at $\lambda=366 \mathrm{~nm}$ ) in the upper part at $\mathrm{R}_{f}=0.75$ (Fig. 2, Table 2). The less intense blue zone of caffeic acid was found at $R_{f}=$ 0.79 and the yellow band of rutin was revealed at $R_{f}=0.09$. The unknown compounds of blue shades were identified at 0.14 , $0.29,0.43$, and 0.64 of $R_{f}$ values, and yellow one corresponding to flavonoids was found at 0.27 in the chromatogram of test solutions. The differences in the values of the $R_{f}$ zones of RA as a predominant component corresponding the test and 


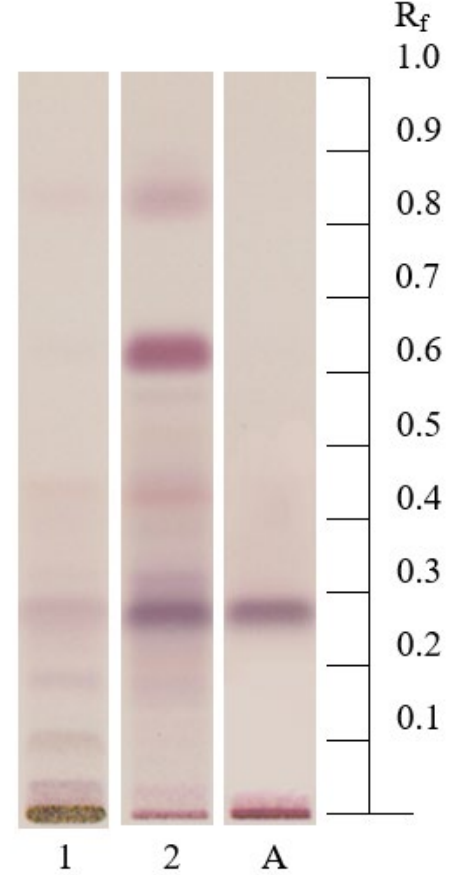

Figure 1. HPTLC chromatograms of the OATEs (1), Ocimum americanum essential oil (2), and linalool standard (A) after the derivatization with anisaldehyde solution at day light. Mobile phase: ethyl acetate - toluene (5:95).

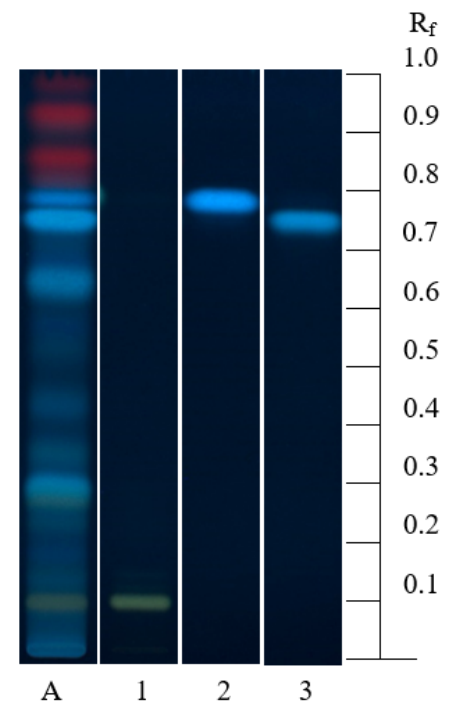

Figure 2. HPTLC chromatograms of the OATEs $(A)$ and polyphenols standards (1-rutin; 2 - caffeic acid; 3 - RA) after the derivatization with $1 \%$ methanolic $\mathrm{AlCl}_{3}$ at $\lambda=366 \mathrm{~nm}$. Mobile phase: ethyl acetate - formic acid - water (15:1:1).

reference solutions within one plate did not exceed 0.01 units of $R_{f}$. The robustness studies of the RA identification in the OATEs are presented in Table 4.

Summarizing the abovementioned results, it was considered that the validated techniques for the identification of linalool and polyphenols in OATEs by the HPTLC method is a suitable procedure to control its quality in the 'Identification' test.
Table 4. The robustness testing of RA identification in OATEs by HPTLC.

\begin{tabular}{|c|c|c|}
\hline \multirow{2}{*}{ Indicator } & $\begin{array}{c}\text { Level of } \\
\text { changes }\end{array}$ & $\begin{array}{c}\text { Rf variability } \\
\text { (RSD, \%) }\end{array}$ \\
\hline \multirow{2}{*}{$\begin{array}{c}\text { Mobile phase } \\
\text { composition } \\
\text { (ethyl acetate-formic } \\
\text { acid - water, V/M) }\end{array}$} & $15: 1: 1$ & 0.8 \\
\cline { 2 - 3 } & $15: 1.05: 1$ & 1.3 \\
\cline { 2 - 3 } & $15: 0.95: 1$ & 1.7 \\
\hline \multirow{2}{*}{$\begin{array}{c}\text { Development } \\
\text { distance, cm }\end{array}$} & $15: 1: 1.05$ & 1.3 \\
\cline { 2 - 3 } & 8 & 1.3 \\
\hline Chamber & $\begin{array}{c}3 \text { different } \\
\text { containers }\end{array}$ & 0.8 \\
\hline Analysts & $\begin{array}{c}2 \text { different } \\
\text { analysts }\end{array}$ & 1.3 \\
\hline \multicolumn{2}{|c|}{0.6} \\
\hline
\end{tabular}

\section{HPLC analysis}

The content of RA as a predominant biologically active ingredient in the OATEs was assayed and validated by the HPLC for the first time. The mobile phase for HPLC consisted of two solutions: $\mathrm{A}$ (trifluoroacetic acid $0.1 \%$ in water), and $B$ (trifluoroacetic acid $0.1 \%$ in acetonitrile) at $1.0 \mathrm{~mL} / \mathrm{min}$ flow rate, volume of injection: $5 \mu \mathrm{L}$. All the solvents should be filtered through a $0.45 \mu \mathrm{m}$ Millipore filter before use and degassed in an ultrasonic bath. Detection was made with spectrophotometer at $330 \mathrm{~nm}$. HPLC was performed at $35^{\circ} \mathrm{C}$ column temperature. RA was determined using external standard method. The gradient elution was provided by mixing mobile phases $A$ and $B$.

The validation of the HPLC test procedure for the analysis of RA content in the OATEs included specificity, linearity, accuracy, precision, and robustness studies. The specificity of the test was confirmed by the coincidence of retention time of the RA peak on the chromatogram of OATEs test solution with the retention of this peak on the chromatogram of RA standard solution (Fig. 3, 4). The chosen chromatographic conditions allowed to separate the peak of the RA from the peaks of other phenolic components. The values for the system suitability were an average of 6 replicates (Table 5). The linearity, recovery, accuracy, and range of HPLC method were defined on model mixtures with known content of active ingredients in the range of $80 \%$ to $120 \%$ of the RA nominal value (Table 6). The regression equation was calculated from the calibration curve for nine concentrations of the RA reference standard. The LOD and LOQ calculated for signal to noise ratio of 3 and 10, respectively. The aliquots of OATEs test solution was split and stored at $4^{\circ} \mathrm{C}$. The aliquots were compared against the fresh-prepared reference standards at various intervals to determine the standard stability. It was recommended to perform all the experiments during a maximum of 3 days and to store stock and standard solutions in a refrigerator. 


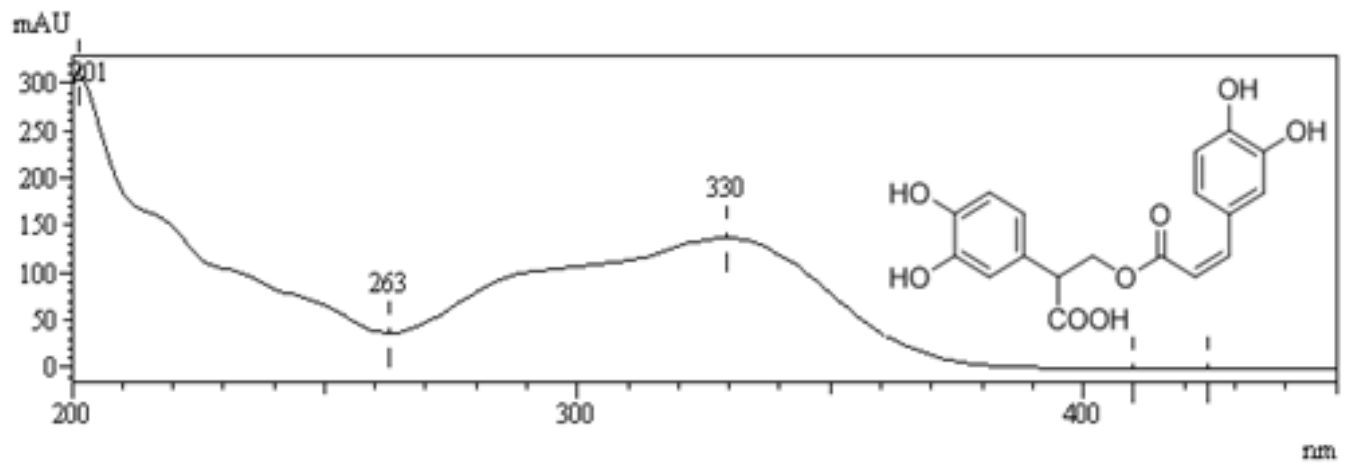

Figure 3. UV absorption spectrum of RA in the HPLC method.

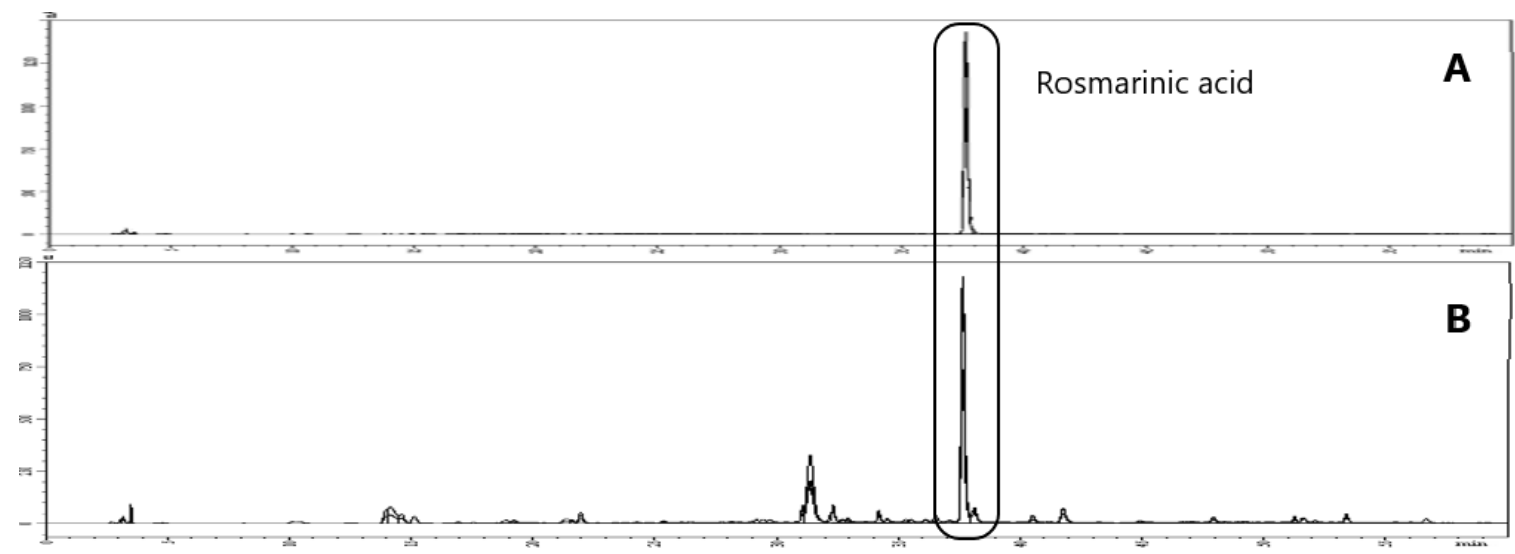

Figure 4. HPLC chromatogram of the RA standard solution (A) and OATEs (B) $(\lambda=330 \mathrm{~nm})$.

Table 5. The system suitability parameters for the determination of RA by HPLC.

\begin{tabular}{|c|c|c|c|}
\hline Standard & Retention time (Rt) & Tailing factor (T) & Theoretical plates (N) \\
\hline Rosmarinic acid & 38.0 & 1.2 & 2399586 \\
\hline
\end{tabular}

Table 6. The linearity, regression equation, limit of detection, limit of quantitation, precision parameters of RA standard in the HPLC analysis.

\begin{tabular}{|c|c|c|c|c|c|c|c|}
\hline Standard & $\begin{array}{c}\text { Linearity range } \\
{[\boldsymbol{\mu g} / \mathbf{m l}]}\end{array}$ & $\begin{array}{c}\text { Regression } \\
\text { equation }\end{array}$ & $\mathbf{R}^{2}$ & $\mathbf{L O D}[\boldsymbol{\mu g} / \mathbf{m l}]$ & LOQ $[\boldsymbol{\mu g} / \mathbf{m l}]$ & \multicolumn{2}{|c|}{ RSD [\%] } \\
\hline Rosmarinic acid & $5-50$ & $\mathrm{Y}=0.235 \mathrm{x}+0.164$ & 0.9998 & 0.005 & 0.015 & 0.16 & 0.04 \\
\hline
\end{tabular}

According to the results of the robustness study, the column temperature and the mobile phase flow within $\pm 5 \%$ did not affect the test results significantly.

\section{Standardization procedure}

The standardization of the OATEs as a perspective herbal medicinal product has been carried out in accordance with the requirements of European Pharmacopoeia (2016) using such a scheme: definition (source of a plant material); production (method of extraction and solvent); characters (appearance, taste, odour), identification (by HPTLC); assay (content of the main biologically active compound by HPLC). Definition. Tincture is produced from the O. americanum herb and its essential oil (OATEs).

Production. Tincture is produced from one part of dried herb using ethanol $(70 \%, V / V)$ by a maceration method to obtain 10 parts of the finished product. Essential oil was dissolved first in ethanol $(96 \%, V / V)$ in ratio $1: 4$, and then added to the tincture until $0.5 \%$ solution was obtained.

Characters. Greenish-brown transparent liquid with a specific aromatic small and bitter-burning taste. 


\section{Identification. Method A}

Test solution. The tincture (OATEs) to be examined $(10 \mu \mathrm{L})$. Reference solution. Dissolve $25 \mu \mathrm{L}$ of linalool in $5 \mathrm{~mL}$ of toluene. Plate: TLC silica gel $F_{254}$ plate $(10 \times 20 \mathrm{~cm})$.

Mobile phase: ethyl acetate - toluene (5:95, V/M); application: $5 \mu \mathrm{L}$, as bands; development: $8 \mathrm{~cm}$ from the line of start; drying: in air.

Detection: treat with anisaldehyde solution, heat at $100-105^{\circ} \mathrm{C}$ for $5 \mathrm{~min}$ and examine in daylight immediately.

Results of TLC analysis. The chromatogram of the test solution in the lower third should be characterized by the weak violet zone of linalool $\left(R_{f}=0.29\right)$. Furthermore, other faint violet zones may be present in the chromatogram obtained with the test solution. Sequence of the zones present in the chromatograms obtained with the reference and test solutions (comparatively with the essential oil of O. americanum) are shown in Fig. 1.

\section{Identification. Method B}

Test solution. The tincture (OATEs) to be examined (10 $\mu \mathrm{L})$. Reference solutions. Dissolve (separately) $1 \mathrm{mg}$ of rutin, $1 \mathrm{mg}$ of caffeic acid, and $1 \mathrm{mg}$ of RA in $4 \mathrm{~mL}$ of methanol.

Plate: TLC silica gel $F_{254}$ plate $(10 \times 20 \mathrm{~cm})$.

Mobile phase: ethyl acetate - formic acid - water (15:1:1, V/M); application: $5 \mu \mathrm{L}$, as bands; development: $8 \mathrm{~cm}$ from the line of start; drying: in air.

Detection: Visualization should be performed under UV light $(254 \mathrm{~nm}, 366 \mathrm{~nm})$ after spraying with $1 \%$ aluminium chloride solution and heating at $100-105^{\circ} \mathrm{C}$ for $5 \mathrm{~min}$.

Results of TLC analysis. The chromatogram of the test solution should be characterized by intense blue zone of $R A\left(R_{f}=0.75\right)$ and less intense blue zone of caffeic acid $\left(R_{f}=0.79\right)$ just above it. The yellow zone of rutin should be evaluated at the bottom $\left(R_{f}=0.09\right)$. Furthermore, other faint blue and yellow zones may be present in the chromatogram obtained with the test solution. Red zones of chlorophyll may be present at the top. Sequence of the zones present in the chromatograms of the reference and test solutions are shown in Fig. 2.

\section{HPLC analysis of RA content}

Test solution. Introduce $1 \mathrm{~mL}$ of OATEs into a volumetric flask $(100 \mathrm{~mL})$ and dilute it by adding $70 \%$ ethanol to the mark. Filter the obtained solution through $0.45 \mu \mathrm{m}$ Millipore filter. Reference solution. Dissolve $15 \mathrm{mg}$ of RA standard in $70 \%$ ethanol and dilute to $100.0 \mathrm{~mL}$ with the same solvent.

Column: Phenomenex Luna C18 column $(250$ x 4.6 mm i.d., 5 $\mu \mathrm{m}$ particle size) at $35^{\circ} \mathrm{C}$ as appropriate.

Mobile phase: Trifluoroacetic acid $0.1 \%$ in water (solution A), and trifluoroacetic acid $0.1 \%$ in acetonitrile (solution B) at 1.0 $\mathrm{mL} / \mathrm{min}$ flow rate in a gradient elution mode (Table 7).

Detection: DAD (330 nm).
Table 7. The gradient mode in the HPLC analysis.

\begin{tabular}{|c|c|c|}
\hline $\begin{array}{c}\text { Time } \\
\text { (min) }\end{array}$ & $\begin{array}{c}\text { Mobile phase A } \\
\text { (vol\%) }\end{array}$ & $\begin{array}{c}\text { Mobile phase B } \\
\text { (vol\%) }\end{array}$ \\
\hline $0-5$ & 95 & 5 \\
\hline $5-35$ & $95 \rightarrow 75$ & $5 \rightarrow 25$ \\
\hline $35-40$ & 75 & 25 \\
\hline $40-60$ & $75 \rightarrow 50$ & $25 \rightarrow 50$ \\
\hline $60-65$ & $50 \rightarrow 20$ & $50 \rightarrow 80$ \\
\hline $65-70$ & 20 & 80 \\
\hline $70-85$ & 95 & 5 \\
\hline
\end{tabular}

Results of HPLC analysis: $0.26 \pm 0.01 \%$ of RA. Identification of RA achieved by comparison of the retention time on the chromatogram and the absorption spectra obtained for its peak in tincture with those obtained for the standard. The quantification of RA made by measuring its peak area at $\lambda=$ $330 \mathrm{~nm}$. The content of RA in tincture should be at minimum $0.2 \%$.

As it is known, the healing properties of the herbal medicinal products can be viewed as a result of the synergistic effect of a lot of biologically active compounds (Yang et al., 2014). As the complexes of active compounds in the obtained tinctures can interact synergistically, the dominating of both RA and linalool in the OATEs could be the reason for the manifestation of its noticeable sedative action. A number of different pharmacologically active compounds with the possible sedative action was established in the Ocimum americanum water-ethanol extracts and essential oil (Shanayda, 2012; Shanaida and Golembiovska, 2018). The noticeable reduction in locomotor activity of the OATEs could either be due to the effect of its biologically active compounds on the central nervous system or a direct influence on the periphery as it was established for the related species Ocimum sanctum (Richard et al., 2016). Researchers observed a marked anxiolytic dose-dependent effect, similar to Diazepam, after using the water-ethanol extracts and essential oil of Ocimum basilicum herb (Rabbani et al., 2015). The sedative influence of the essential oil released by Ocimum basilicum plants was found in mice using open field test (Hirai and Ito, 2019). The sedative, anxiolytic, and antidepressant-like effects were established after the inhalation of Ocimum gratissimum essential oil in mice (Tankam et al., 2014).

The obtained data about the prevalence of RA among phenolic compounds in the OATEs revealed by the chromatographic methods correlates with the results of phytochemical analyses of the $O$. americanum herb (Shanaida et al., 2018; Shanaida et al., 2020). RA was also the 'marker component' of the ethanol extracts obtained from a lot of plants belonging to the Lamiaceae family such as Origanum vulgare, Melissa officinalis, Rosmarinus officinalis, Ocimum basilicum, Salvia officinalis, and Hyssopus officinalis (Staszek et al., 2013; 
Benedec et al., 2015). RA can potentiate the pentobarbitalinduced sleeping through the activation of $\mathrm{GABA}_{\mathrm{A}}$-ergic systems (Yeong et al., 2017). It can also demonstrate the antioxidant effect and other valuable biological activities similar to the other polyphenols containing more than $3 \mathrm{OH}-$ groups in their molecules (Gontova et al., 2016; Rytsyk et al., 2020). Polyphenols possess free radicals scavenging activity, which can prevent neurodegenerative diseases (Cory et al., 2018). The methanol extract of Stachytarpheta cayennensis (order Lamiales) and its butanol, aqueous, and ethylacetate fractions demonstrated the sedative effect in a dosedependent manner (Olayiwola et al., 2013).

Linalool as a key volatile molecule of many essential oils of the Ocimum species possess the sedative activity (Aprotosoaie et al., 2014). Linalool and other terpenoids can modify the function of $\mathrm{GABA}_{A}$ receptors (Kessler et al., 2014). It was found that linalool and linalool-containing essential oil obtained from Lavandula angustifolia (Lamiaceae) aerial part were useful alternative tools to the available traditional treatments for social stress-induced mental illnesses such as anxiety and depression (Caputo et al., 2018; Agatonovic-Kustrin et al., 2020). The relationships between the contents of certain bioactive compounds of terpenoid and polyphenol nature in the Leonurus cardiaca (Lamiaceae) tinctures and their sedative effect were revealed by Romanenko et al. (2018).

The sedative properties of the obtained tinctures can be enhanced by some amino acids, which are extracted from the plant raw material with water and water-ethanol solutions (Shafaei et al., 2017; Shanaida et al., 2017). Besides $\gamma$-aminobutyric acid and glycine as the famous inhibitory neurotransmitter in the central nervous system, it was also established that the sedative effect of a lysine, arginine, alanine, serine, and cysteine acting via $\gamma$-aminobutyric acid receptors (Yamane et al., 2009). All these amino acids were found in the Ocimum americanum herb (Shanaida et al., 2017). The triterpenic ursolic acid possessing sedative action (Colla et al., 2015) was revealed in the 70\% ethanol extract of Ocimum americanum (0.12\%) (Shanaida and Golembiovska, 2018). Thus, the revealed sedative properties of the OATEs can be due to synergistic effects of RA and linalool as well as some amino acids and triterpenoids extracted from the Ocimum americanum raw material with water-ethanol solutions.

\section{CONCLUSIONS}

This study demonstrates the significant sedative effect of the OATEs developed from O. americanum herb using $70 \%$ ethanol and essential oil isolated from this plant. Such sedative property could be due to the common influence of RA and linalool as the predominant biologically active compounds in OATEs as well as some amino acids and triterpenoids. More tests and studies are needed to clarify the exact components with sedative activity in the developed herbal medicinal product. The necessary standardization parameters for the chromatographic analysis of the OATEs were established. The validated HPTLC method was successfully applied for identifying linalool and RA as the predominant compounds of the OATEs. The HPLC method was developed and validated to quantify the RA content in the OATEs. The current study provides a basis for the assessment of developed OATEs as the new perspective herbal medicinal product with sedative action.

\section{CONFLICT OF INTEREST}

There are no conflicts of interest declared by the authors.

\section{References}

[1] Agatonovic-Kustrin S, Kustrin E, Gegechkori V, Morton DW. Anxiolytic Terpenoids and Aromatherapy for Anxiety and Depression. Adv Exp Med Biol. 2020; 1260:283-296. doi: 10.1007/978-3-030-42667-5_11.

[2] American Herbal Pharmacopoeia. Botanical pharmacognosy microscopic characterization of botanical medicines. CRC Press, 2011. 735 p.

[3] Aprotosoaie AC, Hancianu M, Costache li, Miron A. Linalool: a review on a key odorant molecule with valuable biological properties. Flavour Frag J. 2014; 29:193-219.

[4] Asha D,MathewL, Kalappurakkal R. Evaluation of HPTLC fingerprints of flavonoids and antioxidant activity of selected medicinal plants of Lamiaceae Family. Int Journal of Pharmacognosy and Phytochemical Research. 2015; 7(2):240-245.

[5] Benedec D, Hanganu D, Oniga I, Tiperciuc B, Olah NK et al. Assessment of rosmarinic acid content in six Lamiaceae species extracts and their antioxidant and antimicrobial potential. Pak J of Pharm Sci. 2015; 28(6):2297-2303.
[6] Bittner Fialová S, Harris Ch, Ordsmith V, Nagy M, Jonáš F, Mučaji P. Polar phenolic compounds in peppermint rhizomes and leaves. Eur. Pharm. J. 2019; 66(1): 28-31.

[7] Caputo L, Reguilon MD, Mińarro J, De Feo V, Rodriguez-Arias M. Lavandula angustifolia essential oil and linalool counteract social aversion induced by social defeat. Molecules. 2018; 19; 23(10). pii: E2694. doi: 10.3390/molecules23102694.

[8] Choudhary N, Sekhon BS. An overview of advances in the standardization of herbal drugs. J Pharm Edu Res. 2011; 2 (2):5570.

[9] Colla ARS, Rosa JM, Cunha MP, Rodrigues ALS. Anxiolytic-like effects of ursolic acid in mice. European Journal of Pharmacology. 2015; 758(5):171-176.

[10] Cory H, Passarelli S, Szeto J, Tamez M, Mattei J. The role of polyphenols in human health and food systems: A mini-review. Front. Nutr. 2018; 5(87).

[11] Derzhavnyi rejestr likarskyh zasobiv Ukrainy (2020). [ONLINE] Available at: http://www.drlz.com.ua (in Ukrainian) 
[12] Doughari HJ. Phytochemicals: extraction methods, basic structures and mode of action as potential chemotherapeutic agents. In: Phytochemicals - a global perspective of their role in nutrition nd health. Ed. by V. Rao. 2012:1-32.

[13] European Pharmacopoeia. 2016. 8th Ed. [ONLINE] Available at: https://www.edqm.eu/en/european-pharmacopoeia-ph-eur8th-edition

[14] Ethical Principles and Guidelines for Experiments on Animals. 2005. 3rd ed. Available at: https://publisher.medfak.ni.ac.rs/ ASN_1/Ethical\%20Principles-S.pdf

[15] Gontova T, llyinska N, Golembiovska O, Mashtaler V. Study of the component composition of phenolic compounds obtained from Dahlia varieties Ken's Flame herb. Der Pharma Chemica. 2016; 8(18):455-459.

[16] Gutiérrez SL, Chilpa RR, Jaime HB. Medicinal plants for the treatment of "nervios", anxiety, and depression in Mexican Traditional Medicine. Rev Bras Farmacogn. 2014; 24 (5):591-608.

[17] Hirai M, Ito M. Sedative effects of the essential oil and headspace air of Ocimum basilicum by inhalation in mice. J Nat Med. 2019; 73(1):283-288.

[18] Hudz N, Yezerska O, Shanaida M, Horčinová Sedláčková V, Wieczorek PP. Application of the Folin-Ciocalteu method to the evaluation of Salvia sclarea extracts. Pharmacia. 2019; 66(4):209-215.

[19] Kessler A, Sahin-Nadeem H, Lummis SC, Weigel I, Pischetsrieder Met al. GABA(A) receptor modulation by terpenoids from Sideritis extracts. Mol. Nutr. Food Res. 2014; 58:851-862. doi: 10.1002/ mnfr.201300420

[20] Koteswar SB, Babu AV. Pharmacognostic and phytochemical studies of Ocimum americanum. J Chem Pharm Res. 2011; 3(3):337-347.

[21] Linck VM, da Silva AL, Figueiró M, Piato AL, Herrmann AP et al. Inhaled linalool-induced sedation in mice. Phytomedicine. 2009; 16:303-307.

[22] Logoyda L, Abdel-Megied A, Kondratova Y, Trofimenko O, Korobko D, Dakhym I. Development and validation of HPLC method for the simultaneous determination of enalapril maleate in present of their impurities: application to tablet analysis. International Journal of Applied Pharmaceutics. 2018; 10(1):98-102.

[23] Olayiwola G, Ukponmwan O, Olawode D. Sedative and anxiolytic effects of the extracts of the leaves of Stachytarpheta cayennensis in mice. Afr J Tradit Complement Altern Med. 2013; 10(6): 568579.

[24] Rabbani M, Sajjadi SE, Vaezi A. Evaluation of anxiolytic and sedative effect of essential oil and hydroalcoholic extract of Ocimum basilicum L. and chemical composition of its essential oil. Res Pharm Sci. 2015; 10 (6):535-543.

[25] Richard EJ, Illuri R, Anandhakumar B, Anandhakumar S, Bhaskar A et al. Anti-stress activity of Ocimum sanctum: possible effects on hypothalamic-pituitary-adrenal axis. Phytotherapy Research. 2016; 30(5):805-814.

[26] Romanenko Ye, Koshovyi O, Kireyev I, Tryshchuk N, llyina T, Borodina N. Study of the relations between the main BAS groups content in Leonurus cardiaca tincture and its psychotropic activity. Ukraïns'kij bìofarmacevtičnij žurnal. 2018; 4 (57): 69-74 (in Ukrainian).
[27] Rytsyk O, Soroka Y, Shepet I, Vivchar Z, Andriichuk I et al. Experimental evaluation of the effectiveness of resveratrol as an antioxidant in colon cancer prevention. Natural product communications. 2020; 15(6):1934578X2093274

[28] Sarker Apu A, Hossan Bhuyan S, Matin M, Hossain F, Khatun F, Taiab A. Analgesic, neuropharmacological, anti-diarrheal, and cytotoxic activities of the extract of Solanum sisymbriifolium (Lam.) leaves. Avicenna J Phytomed. 2013; 3(4):302-312.

[29] Shafqatullah, Khan R, Hassan W. Development of HPLC method by UV-VIS detection for the quantification of phenolic acids in different Ocimum sanctum Linn. extracts. Pak J Pharm Sci. 2014; 27(5):1271-1275.

[30] Shafaei A, Ab Halim NH, Zakaria N, Ismail Z. Analysis of free amino acids in different extracts of Orthosiphon stamineus leaves by high-performance liquid chromatography combined with solidphase extraction. Pharmacogn Mag. 2017; 13(Suppl 3):385-391.

[31] Shanaida M, Kernychna I, Shanaida Y. Chromatographic analysis of organic acids, amino acids, and sugars in Ocimum americanum L. Acta Poloniae Pharmaceutica - Drug Research. 2017; 74(2):729-734.

[32] Shanaida M, Golembiovska O. Identification and component analysis of triterpenoids in Monarda fistulosa L. and Ocimum americanum L. (Lamiaceae) aerial parts. ScienceRise: Pharmaceutical Science. 2018; 3(13):26-31.

[33] Shanaida M, Golembiovska O, Hudz N, Wieczorek PP. Phenolic compounds of herbal infusions obtained from some species of the Lamiaceae family. Current Issues in Pharmacy and Medical Sciences. 2018; 31(4):194-199.

[34] Shanaida M, Jasicka-Misiak I, Makowicz E, Stanek N, Shanaida V, Wieczorek PP. Development of high-performance thin layer chromatography method for identification of phenolic compounds and quantification of rosmarinic acid content in some species of Lamiaceae family. J Pharm Bioall Sci. 2020; 12 (2):139-145.

[35] Shanayda MI. Comparative analysis of essential oils components of Ocimum L. genus. Farmatz zhurnal. 2012; 4: 99-102. (in Ukrainian).

[36] Staszek D, Orłowska M, Waksmundzka-Hajnos M, Sajewicz M, Kowalska T. Marker fingerprints originating from TLC and HPLC for selected plants from the Lamiaceae family. J Chromatography. 2013; 36 (17):2463-2475.

[37] Tankam JM, Ito M. Sedative, anxiolytic and antidepressant-like effects of inhalation of the essential oil of Ocimum gratissimum L. from Cameroon in mice. Journal of Pharmacognosy and Phytochemistry. 2014; 2(5):1-9.

[38] The Genus Ocimum (Basil) / Ed. by R. Hiltunen and Y. Holm. Taylor \& Francis e-Library. 2006.

[39] Yamane H, Kurauchi I, Denbow DM, Furuse M. Central functions of amino acids for the stress response in chicks. Asian-Aust. J. Anim. Sci. 2009; 22(2): 296-304.

[40] Yang Y, Zhang Z, Li S, Ye X, Li X, He K. Synergy effects of herb extracts: pharmacokinetics and pharmacodynamic basis. Fitoterapia. 2014; 92:133-147.

[41] Yeong Ok Kwon, Jin Tae Hong, Ki-Wan Oh. Rosmarinic acid potentiates pentobarbital-induced sleep behaviors and nonrapid eye movement (NREM) sleep through the activation of $\mathrm{GABA}_{\mathrm{A}}$-ergic systems. Biomol Ther (Seoul). 2017; 25(2):105-111. 